\title{
Teaching Alphabet Recognition and Letter Sound Correspondence Using a 4 Blocks of Literacy Model for Children with Complex Communication Needs (CCN): Illustrated with a Single Case Study
}

\author{
Arya Manoharan', Jubil Jose², Sneha Saji ${ }^{3}$ \\ ${ }^{1}$ Lecturer/Speech Language Pathologist; Department of NDS, National Institute of Speech and Hearing, \\ Akkulum, Trivandrum 695017, Kerala, India. \\ ${ }^{2}$ Student, 6th Semester BASLP; Department of ASLP, National Institute of Speech and Hearing, Akkulum, \\ Trivandrum 695017, Kerala, India. \\ ${ }^{3}$ Student, 6th Semester BASLP; Department of ASLP, National Institute of Speech and Hearing, Akkulum, \\ Trivandrum 695017, Kerala, India. \\ Corresponding Author: Arya Manoharan
}

DOI: https://doi.org/10.52403/ijhsr.20220114

\begin{abstract}
There are numerous hurdles to literacy acquisition for students with severe and multiple disabilities, such as intellectual disability, complex communication needs including physical disability and autism. However, there is substantial body of research that suggests that these children can gain literacy skills, develop communication and language with effective literacy education, and with the support of assistive and augmentative alternative communication systems. The study describes an ongoing intervention for teaching alphabet recognition and letter-sound correspondence using the 4 blocks of literacy model with a 5.7 year old girl with multiple disabilities who use augmentative alternative communication systems for communication. Emergent literacy instruction for improving alphabet recognition and letter sound correspondence was taught applying the principles of the 4 blocks "Working with words" and "Shared book reading" over a period of eight months. Improvement noticed in alphabet recognition and letter sound correspondence was investigated. Emergent literacy instruction using 4 blocks of literacy model was proved to be an effective method in gaining the alphabet principles and phonics skills. The study provides insights to the rehabilitation professionals and budding therapists on how to implement emergent literacy instructions and strategies to be considered for children with complex communication needs.
\end{abstract}

Key Words: Emergent Literacy, Complex Communication Needs, Augmentative Alternative Communication, Multiple Disabilities, 4 Blocks of Literacy Model.

\section{INTRODUCTION}

Literacy is recognized as being a foundational skill for all aspects of adult life. Having the ability to read and write in a literate society is considered a highly valued social role which in turn helps in improving the quality of life. Nevertheless, literacy training for individuals with Complex Communication Needs (CCN) is frequently overlooked. Researchers in the field of literacy development suggest that with the acquisition of literacy skills, individuals with CCN can use a variety of communication options, independently produce and share their messages and thereby change attitudinal barriers. Alternative and Augmentative Communication (AAC) is found to be an effective tool to support literacy skills in children with CCN. ${ }^{[1,2]}$ Without literacy, 
CCN has to rely on communication partners to provide access to appropriate vocabulary or symbols for communication. But, if the CCN have access to literacy skills, they can communicate any message to any individual. ${ }^{[3]}$ As a consequence, learning to read and write offers CCNs the benefit for communication, language development, and independence in addition to substantial educational, vocational, social, and personal benefits. [2,4] Research in the field demonstrated that a balanced and comprehensive approach to literacy instruction is highly supportive for children with CCN, especially for those with multiple disabilities because of the coexisting opportunities to build communication and literacy skills through this approach. ${ }^{[5-10]}$

Balanced literacy, also referred to as comprehensive literacy instruction in literature is first developed by Patricia Cunningham \& Dorothy Hall in 1989. This is further adapted by Karen Erickson and David Koppenhaver (1995) for students with significant disabilities. The central activities of a balanced comprehensive emergent literacy instruction are implemented daily and include shared reading and writing, instruction in alphabet knowledge and phonological awareness, and independent reading and writing. ${ }^{[8,11]}$

There are only very few studies that addressed the emergent literacy instruction for teaching letter sound correspondence and alphabet knowledge. All these studies employed different approaches such as systematic phonics instruction, naturalistic strategies and Non-verbal reading Approach (NRA) to teach phonics to students with multiple and severe disabilities who are dependent on AAC systems. [12-14] Moreover, studies in balanced literacy instruction were more or less concentrated on word recognition and decoding skills which mostly is a part of conventional literacy instruction. There is a lack of literature in emergent literacy instruction using 4 blocks of literacy framework for children with CCN and severe disabilities.
In addition, results obtained from the studies in western literature cannot be generalized to the Indian population as there are differences in literacy beliefs and practices in India and abroad. Therefore, the present study will be a preliminary study that is aimed at investigating the effect of balanced literacy instruction using the 4 blocks of literacy model on alphabet recognition and letter-sound correspondence in children with CCN. Further, the study provides an insight to the teachers and rehabilitation professionals about skills to be targeted, instructional procedures and adaptations to be considered while teaching alphabet recognition and letter sound correspondence to children with complex communication needs and severe disabilities.

\section{CASE STUDY}

To maintain anonymity, the subject considered for the study was discussed in the pseudo name Anna. Anna was 5.7 years old when she was referred for literacy intervention by her parents. Anna was diagnosed with a neurological condition called Bilirubin Induced Neurological Dysfunction (BIND) that resulted in substantial difficulties in speech, motor, and hearing impairment. She had athetoid cerebral palsy and demonstrated hypertonicity in her upper and lower extremities along with involuntary motor movements. She used a wheelchair for ambulation. Anna had bilateral severe hearing loss and was fitted with hearing aid bilaterally. As an infant, she had undergone blood transfusion twice and was ventilated due to hypercalcemia and neonatal seizures.

Anna was using multiple modalities to communicate such as facial expressions, crying, and vocalizations to attract attention before intervention. In early intervention training, she was introduced to Augmentative Alternative Communication (AAC) using a Sound Generating Device (SGD) Bigmac. She activated the device to express wants and need, request for more and to indicate "Yes/No' to questions asked. To expand her vocabulary use, she was 
introduced to communication charts where she points to desired symbol for communication. After reviewing her progress in communication skills using $\mathrm{AAC}$, the therapist and the parent jointly decided to start literacy training using a balanced literacy instruction developed for children with significant disabilities (4 blocks of literacy model).

\section{Baseline}

Anna did not have any previous literacy experience as the parents never exposed her to literacy enriching environment. Prior to initiating literacy training for Anna, her communication skills were assessed using the Communication Matrix. ${ }^{[15]}$ As there were no commercially available assessment tools to reliably and with validity determine literacy skills for children with CCN and significant disabilities an informal assessment of literacy skills based on a systematic observation process of 6 components developed by ${ }^{[16]}$ and adapted by ${ }^{[17]}$ is used to gather information about her early literacy understanding and to monitor the progress.

\section{Literacy Instruction}

The literacy intervention for Anna was a comprehensive balanced literacy program that is based on "4 blocks of the literacy framework - A Comprehensive Literacy program for children with CCN". The 4 blocks of this framework are Selfselected reading (SSR), Shared reading/Guided Reading, Writing, and Working with words. Literacy instruction for Anna was completed in two phases.

Initial Phase: Alphabet recognition and teaching letter-sound correspondences

The initial phase of literacy instruction was on emergent literacy instruction in the block "Working with words" focusing on the following skills: Alphabet knowledge and teaching lettersound correspondences. To improve alphabet knowledge, Case $\mathrm{X}$ was exposed to Alphabet songs. Along with that, a careful attempt was made to teach these alphabets in a meaningful way, "Letter of the week" was introduced starting with the first letter of her name. She was also encouraged to do "sign-in" and "sign out" using a stamp opposite to her name whenever she appears for the therapy session. Further, she was given opportunities to interact with the alphabet through embedding the alphabet in the games and daily activities. She was then introduced to letter-sound correspondence by matching the corresponding picture to the letter sound. The target letter is first introduced followed by the picture corresponding to the letter (picture of Ball for sound $/ \mathrm{b} /$ ). Case $\mathrm{X}$ was then given $\mathrm{a}$ hierarchy of prompts to activate Bigmac for "yes" or point to yes/no picture in her communication board in response to the question Does the letter "M" sound $/ \mathrm{mmm} /$ ? or Does the letter "M" in Mango sound $/ \mathrm{mmm} /{ }^{[18]}$

\section{Second Phase: Shared book-reading activities for practicing alphabetic principles and home training}

In the second phase, Anna was given opportunity use the alphabet principles in meaningful context. As part of this, customized books were read to her focusing on alphabet identification and letter-sound correspondence. In the home training program, practice videos were sent to the parent modeling the shared book reading and skill focused during the reading instruction. Mother was instructed to practice shared reading activities as modeled in the practice videos and the recorded sessions was analysed to monitor the progress. Android based literacy apps was also used as part of home training program.

Intervention sessions were
conducted by a Speech-Language Pathologist with experience in conducting literacy instruction for children with CCN. A one-to-one session of 45 minutes once a week was arranged for Anna. For home training, practice videos of activities on shared book reading and alphabet 
Arya Manoharan et.al. Teaching alphabet recognition and letter sound correspondence using a 4 blocks of literacy model for children with complex communication needs (CCN): Illustrated with a single case study.

recognition were provided. Anna attended a total of 32 sessions over 8 months.

\section{RESULT}

\section{Outcome of literacy intervention on} Alphabet recognition and Letter Sound Correspondence

After attending 8 months i.e., approximately 32 hours of intervention and home training, Anna showed a considerable improvement in alphabet recognition and letter-sound correspondence (a) She had acquired all 26 alphabets in English and identified them when presented in multiplechoice of 5 or 6 letters. During the shared reading task, Anna was encouraged to identify the alphabet names or to identify a particular letter in the text. She identified the named alphabet in the text with $60 \%$ of accuracy. (b) Anna acquired 10 letter-sound correspondences (i.e., a, b, d, f, g, h, i, j, m, o) and identified these letters with $>80 \%$ accuracy from a field of 5 to 6 letters when the sounds were presented to her in multiple-choice visually. While engaged in the shared reading task, she identified a letter by its sound in response to the question "show me the letter that makes the sound $/ \mathrm{m} / "$ in the text. The goal focused during shared book reading was to teach to apply alphabetic principles in reading. By the end of 8 months, she started showing print awareness by demonstrating print orientation skills.

\section{Outcome in communication and language}

Anna's communication skills were at a very fundamental level of conventional communication prior to the intervention. As summarized in table 1 , she was able to reject, request attention, and obtain basic wants and needs to be known by pointing to pictures or symbols. However, the communication function was only limited to requesting, rejecting, and affirmation. There was a substantial improvement in the communication functions used by Anna after the literacy intervention was introduced. This was evidenced by the steady increase in the level of communication matrix scores.

Table 1: Baseline profile on communication skills and progress after 8 months of literacy based intervention

\begin{tabular}{|l|l|l|}
\hline $\begin{array}{l}\text { Communication } \\
\text { Matrix }\end{array}$ & Baseline & $\begin{array}{l}\text { 8 months post literacy } \\
\text { intervention }\end{array}$ \\
\hline Refuse & $\begin{array}{l}\text { Level- } \\
\text { mastered }\end{array}$ & Level-7 mastered \\
\hline Obtain & $\begin{array}{l}\text { Level-3 } \\
\text { mastered }\end{array}$ & Level-7 mastered \\
\hline Social & $\begin{array}{l}\text { Level- } \\
\text { emerging }\end{array}$ & Level- 5 mastered \\
\hline Information & $\begin{array}{l}\text { Level-1 } \\
\text { Mastered }\end{array}$ & Level-5 mastered \\
\hline
\end{tabular}

\section{DISCUSSION}

The results of this case study indicated that children with multiple disabilities can develop alphabet knowledge and letter-sound correspondence from explicit emergent literacy instruction. Anna was taught alphabet knowledge and lettersound associations using emergent literacy instruction using the block "Working with words" and "Shared book reading" of the 4 blocks of literacy framework. Alphabet knowledge and letter-sound correspondence were then assessed using multiple-choice options and measured as the number of correctly identified target letter-sound associations. Teaching alphabet recognition and letter-sound correspond are very important as "letters and sounds" are identified to be one of the primary blocks that need to be focused on in emergent literacy instruction. This is because, it is through learning letters and letter sounds, children learn to apply the alphabetic principle to begin to spell words and to decode words. ${ }^{[19]}$ Though there are only a very limited number of studies that are based on alphabet recognition and lettersound correspondence acquisition for CCN and severe disabilities, increased recognition of the importance of this foundational skill has piqued interest in the subject. ${ }^{[20,6]}$.

In the present study, the block "shared book reading" was chosen as the main activity for using the learned alphabet knowledge and principles in reading. After attending 16 hours of home training sessions using shared book reading activity, Anna 
was able to identify the learned alphabets in a text with $60 \%$ of accuracy. Improvement noticed in terms of alphabet knowledge, letter naming, and letter-sound correspondence are attributed to the constant modeling of reading and pointing to the alphabets and letter-sound by the caretaker and the therapist. The findings support the view that shared book reading when used in conjunction with scaffolding yield better literacy learning and communication skills in students with multiple and severe disabilities who use AAC. ${ }^{[7]}$ For shared book reading practice as home training, practice videos using adapted textbooks were used. These books were custom-made based on the child's interest. ${ }^{[21,7]}$ It was noticed that the use of shared book reading activities using the emergent literacy instruction also helped to improve the communication skills. This was evidenced in the communication matrix scores. ${ }^{[22]}$ This substantial improvement in levels of communication function could be due to the frequency use of AAC devices for multiple communication functions such as commenting, responding to questions during the shared book reading activity. Another aspect that must have contributed to progress in levels of communication functions could be the quantity and quality of mother-child interaction during the shared reading task. The results of the present study also point to the importance of including shared book reading as an activity to improve vocabulary, communication, and early emergent literacy among children with CCN.

\section{CONCLUSION}

The current study contributes to the growing body of research that disability in multiple domains should not be a barrier to learning literacy skills. Also, children with multiple disabilities and CCN can be taught literacy skills in the same way as typically developing peers. Just that they differ in the instructional strategies and adaptations. The study also provides insights to the rehabilitation professionals and budding therapists on how to implement emergent literacy instructions and strategies for CCN to develop alphabet knowledge and letter sound correspondence.

\section{Acknowledgement: None}

\section{Conflict of Interest: None}

\section{Source of Funding: None}

\section{REFERENCES}

1. Foley B, Wolter JA. Literacy intervention for transition-aged youth: What is and what could be. Language, literacy, and AAC issues for transition-age youth. 2010;35.

2. Light J, McNaughton D. Literacy intervention for individuals with complex communication needs. Augmentative and alternative communication: Supporting children and adults with complex communication needs. 2013:309-51.

3. Sturm J, Beukelman DR, Mirenda P. Literacy development of AAC users. Augmentative and alternative communication: Management of severe communication disorders in children and adults. $2^{\text {nd }}$ ed. Baltimore: Paul Brookes; 1998.

4. Hanser GA, Erickson KA. Integrated word identification and communication instruction for students with complex communication needs: Preliminary results. Focus on Autism and Other Developmental Disabilities. 2007;22(4):268-78.

5. Keefe EB, Copeland SR. What is literacy? The power of a definition. Research and practice for persons with severe disabilities. 2011;36(3-4):92-9.

6. Browder DM, Wakeman SY, Spooner F, Ahlgrim-Delzell L, Algozzine B. Research on reading instruction for individuals with significant cognitive disabilities. Exceptional children. 2006;72(4):392-408.

7. Browder DM, Ahlgrim-Delzell L, Courtade G, Gibbs SL, Flowers C. Evaluation of the effectiveness of an early literacy program for students with significant developmental disabilities. Exceptional Children. 2008; 75(1):33-52.

8. Downing JE, editor. Teaching literacy to students with significant disabilities: Strategies for the K-12 inclusive classroom. Corwin Press; 2005. 
Arya Manoharan et.al. Teaching alphabet recognition and letter sound correspondence using a 4 blocks of literacy model for children with complex communication needs (CCN): Illustrated with a single case study.

9. Light J, McNaughton D, Weyer M, Karg L. Evidence-based literacy instruction for individuals who require augmentative and alternative communication: A case study of a student with multiple disabilities. In Seminars in speech and language 2008;29(2): 120-132.

10. Koppenhaver DA, Erickson KA. Natural emergent literacy supports for pre-schoolers with autism and severe communication impairments. Topics in Language Disorders. 2003;23(4):283-92.

11. Erickson KA, Koppenhaver DA. Comprehensive Literacy for All: Teaching Students with Significant Disabilities to Read and Write. Baltimore: Brookes Publishing Company; 2020.

12. Fallon KA, Light J, McNaughton D, Drager $\mathrm{K}$, Hammer C. The effects of direct instruction on the single-word reading skills of children who require augmentative and alternative communication. Journal of Speech, Language, and Hearing Research. 2004; 47(6):1424-1439.

13. Johnston SS, Davenport L, Kanarowski B, Rhodehouse S, McDonnell AP. Teaching sound letter correspondence and consonantvowel-consonant combinations to young children who use augmentative and alternative communication. Augmentative and Alternative Communication. 2009;25(2):123-35.

14. Ahlgrim-Delzell L, Browder DM, Wood L, Stanger C, Preston AI, Kemp-Inman A. Systematic instruction of phonics skills using an iPad for students with developmental disabilities who are AAC users. The Journal of Special Education. 2016;50(2):86-97.

15. Rowland C. Online Communication Matrix. Oregon Health \& Science University Design to Learn Project; 2009. Available from http://www.communicationmatrix.org
16. Clay MM. An observation survey of early literacy achievement. $4^{\text {th }}$ ed. Heinemann, 361 Hanover St., Portsmouth; 1993. NH 03801-3912

17. Erickson KA. All children are ready to learn: An emergent versus readiness perspective in early literacy assessment. Seminars in Speech and Language 2000; 21(03):193-204).

18. Carnahan CR, Williamson PS, Hollingshead A, Israel M. Using technology to support balanced literacy for students with significant disabilities. Teaching Exceptional Children. 2012;45(1):20-9.

19. Hall DP, \& Williams E. The teacher's guide to building blocks: A developmentally appropriate, multilevel framework for kindergarten. North Carolina: CarsonDellosa Publishing Company; 2000.

20. Allor JH, Champlin TM, Gifford DB, Mathes PG. Methods for increasing the intensity of reading instruction for students with intellectual disabilities. Education and Training in Autism and Developmental Disabilities. 2010: 500-511.

21. Hudson ME, Browder D, Wakeman S. Helping students with moderate and severe intellectual disability access grade-level text. Teaching Exceptional Children. 2013;45(3):14-23.

22. Farrant BM, Zubrick SR. Early vocabulary development: The importance of joint attention and parent-child book reading. First Language. 2012;32(3):343-64.

How to cite this article: Manoharan A, Jose J, Saji S. Teaching alphabet recognition and letter sound correspondence using a 4 blocks of literacy model for children with complex communication needs (CCN): Illustrated with a single case study. Int J Health Sci Res. 2022; 12(1): 99-104. DOI: https://doi.org/10.52403 /ijhsr.20220114 